\title{
Measuring the Accuracy of Self-assessment Among Undergraduate Students in Higher Education to Enhance Competitiveness
}

\author{
- Máté Domicián, Darabos Éva
}

\begin{abstract}
This study analyses the educational self-assessment of Hungarian under-graduate business students, focusing primarily on the concept of accuracy as students predict and evaluate their own accountancy performance in traditional and digital (Moodle) examinations. The main purpose of our research is to explore whether high-achieving students are more accurate in their self-assessment when predicting and evaluating their knowledge. Moreover, in our esti-mations, we also examine whether a gender gap in both self-estimation assessment results exists. In the pre- and post-examination predictions, the higher-achieving students seem to predict and evaluate their examination results more accurately than their lower-achieving fel-lows on the Moodle tests. Our conclusions also enable the enhancement of the employability of the coming generation of accountants and the competitiveness of higher education to achieve the desired outcomes. Moreover, higher education staff can identify evidence about which groups of students are in need of supplementary support when studying accountancy in the digital age.
\end{abstract}

Keywords: self-assessment; overestimation; higher education; competitiveness; accounting JEL Classification: I21, C13, M41

\section{INTRODUCTION}

European collaboration in education and training until 2020 should be recognized in a strate-gic framework that encompasses a lifelong learning perspective. Indeed, this fundamental principle could support learning IT systems from early childhood education through to higher education, training and adult learning. The EC (2009) report emphasized that an efficient in-vestment in Higher Education Institutions (HEIs) through new technologies is an essential component of the European (ET 2020) strategy to deliver high levels of sustainable, knowledge-based economies and increasing competitiveness.

Indeed, the practice of accounting is changing rapidly, and globalization is having an increas-ing impact on traditional teaching methods. This is occurring while many accounting pro-grams, courses, approaches, etc. require systematic adaptation to the new technological op-portunities available in the digital age (Abbasi, 2013). At the same time, the Bedford Commit-tee on Future Accounting Education encouraged this paradigm-shift with the observation that contemporary accounting competences are insufficient for educating professional accountants in the twentyfirst century (AAA, 1986). Subsequently, several other critics (e.g., Black, 2012; Strawser, et al. 2012) emphasized that accounting education has not been able to adequately respond to changes in the environment and to business needs. Consequently, McPeak et al. (2012) argued that gen- 
eral agreements about professional competences are required in order to evaluate and develop the courses, necessary experience, and the examinations related to the accountancy profession.

\section{BRIEF LITERATURE REVIEW OF SELF-ASSESSMENT}

There is little agreement in the literature regarding the relationship between students' performance and the accuracy of their self-assessment. Kruger and Dunning (1999), Karnilowicz (2012) and Kun (2016), etc. concluded that higher-achieving students are more accurate in their selfassessment than low achievers, but O'Neill et al. (2006) rejected this phenomenon. The notion of accuracy in several studies is still confusingly determined by references to measurement by self-assessment. In this paper, accuracy is defined as the result of an absolute difference between the student-estimate and the ultimate tutor-estimate exam scores, and it is used to describe the student's self-estimation ability independently of its direction (over- and underestimation).

Assessment is one of the most powerful tools teachers have to influence the ways an account-ant responds to accountancy courses and students behave. Obviously, students are more likely to pay attention to those aspects of a course or training that will be assessed. Furthermore, the ways in which students apply innovative technologies for educational purposes are related to how they perceive the ways their courses are assessed. In this case, self-assessment influences not only what elements of a course get studied, but also how those elements are studied (Gibbs, 1999). Among these factors, a better self-assessment improves their future employa-bility and reduces the length of their job search (Kiss, 2014).

New technologies are much more likely to enhance the competitiveness when higher education teachers recognize the importance of their role in devising and designing activities in order to promote learning in ways that enable the coming generation of auditors to achieve the desired educational outcomes (Kirkwood \& Price, 2011). Obviously, the levels of accuracy vary within countries and across specific socio-economic groups. According to Sistrom et al. (2003) and Macdonald (2004), there may be a gender gap in the direction of their self-estimation. However, several studies have not been able to identify any gender-related effects of over-estimation, including those by Kruger and Dunning (1999), O’Neill et al. (2006) and Hobohm et al. (2012).

\section{MOTIVATION AND HYPHOTESES}

Our motivation for this study stems from the fact that in higher education, a high proportion of students who study accountancy sometimes seem prone to irrationally evaluate their own performance. However, there is still no existing consensus on whether students' self-assessment ability is learnable during higher education courses (see, e.g., Everett, 1983; Zimmerman \& Schunk, 2001; Macdonald, 2004). Ross (2006) also pointed out that specific student groups are exposed to the phenomenon of inaccurate self-assessment. Therefore, our study focuses on the measurement of undergraduate students' accounting knowledge to pre-dict and evaluate their own performance, comparing traditional written and digital examina-tions relative to their externally assessed achievement. 
The main purpose of this study is to explore the idea that high-achieving students are more accurate in self-assessing their accounting knowledge. Our research represents an analysis of traditional written and online examinations taken at the University of Debrecen, focusing on agrarian engineering students' self-assessment. We have also paid particular attention to vari-ations in gender. In the following sections, we first present the data available and the methods applied. Finally, we attempt to draw a number of brief conclusions from the results of our research, which will hopefully clarify empirical and professional debates on the contributions of higher education to provide better outcomes in accountancy studies in order to enhance employability and competitiveness.

Based on the findings of the literature reviewed above, and assuming that (H1) higher achieving students assess their examination results more accurately (measured by the absolute value of self- and tutor-assessment differences) than their lower achieving fellows, our study forms four additional sub-hypotheses:

$\mathrm{H}_{1}$ : Higher achieving students predict their examination results more accurately (measured by the absolute value of the pre-examination assessment results) than their lower achieving colleagues.

$\mathrm{H}_{2}$ : Higher achieving students evaluate their examination results more accurately than their lower achieving colleagues.

$\mathrm{H}_{3}$ : Higher achieving students overestimate their own pre-examination performance (measured by the absolute value of the post-examination assessment results, if the stu-dents overestimated their total test scores after the exam) less than their lower achiev-ing colleagues.

$\mathrm{H}_{4}$ : Higher achieving students overestimate their own post-examination performance less than their lower achieving colleagues.

In order to demonstrate disparities in terms of accuracy, we also assumed (H2) that women tend to estimate their own performance more confidently than men. The study forms four sub-hypotheses in this sense:

$\mathrm{H}_{2}$ : Female students predict their examination results more accurately than their male colleagues.

$\mathrm{H}_{2}$ : Female students evaluate their examination results more accurately than their male colleagues.

$\mathrm{H}_{2}$ : Female students overestimate their own pre-examination performance more than male students.

$\mathrm{H}_{2}$ : Female students overestimate their own post-examination performance more than male students.

\section{SAMPLE AND METHODS}

Our estimations are based on a sample of 135 bachelor (47 men and 88 women) students from the Faculty of Economics and Business at the University Debrecen, Hungary. At the time of the examination, 110 students were studying the Agrarian Economics Engineer course, and 25 the Informatics Engineer course. 
Their compulsory Accounting course module taught the basic concepts of financial account-ing. By the end of this course, students were able to understand the role of accounting in the international business environment. Moreover, accountancy lectures and seminars covered the following subjects: principles of accounting, double entry bookkeeping, recognition and measurement of assets, liabilities and equity, the impact of economic transactions on financial statements, the accounting cycle and policies, general and special journals, etc.

The examination was carried out on two specific dates and times. Moreover, two different test versions (identified as Traditional and Moodle) were also chosen. Consequently, eliminating infrequent effects deriving from the varied test versions, these factors are considered in sepa-rated models during our analyses.

The first traditional (TRAD) test version contained i.e. adjusting, composition and closing procedures of Financial Statements, journalizing and posting, recognition of assets and liabili-ties, bookkeeping and posting exercises, etc.

The second analysis was completed by a Moodle (IT) system. Moodle was originally devel-oped by M. Dougiamas to support educational staff in creating online courses and assignments focusing on interaction and cooperation with, in this particular case, students who were studying accountancy. Moodle, as an e-learning virtual platform can also enhance existing types of assessment environments (Walker et al., 2014).

Our Moodle test version had the following structure:

- at least 10 true or false (T/F) and multiple choice (MC) questions randomized from 74 samples of each type and based on a conceptual framework of Balance Sheet, P\&L Statements, Statement of Cash Flow, etc. Each correct response was worth one point and in the MC section, one or more correct answers (from possible four choices) were also available.

- the Practical (PRAC) sections of our test versions were focused on Annual Financial Statements (Balance Sheet, P\&L Statement etc.) and other transactions, giving a maximum of 20 points (from 53 Mini Cases).

Before the students started their examination, they were asked to predict each of their test scores. In order to motivate them to predict more accurately, they were offered a higher per-centage in a later test as a bonus if they could estimate well. Specifically, either 10 per cent was added for a perfect hit for each type of questions or 5 percent if the approximation was within a \pm 1 point range. After the tests had been completed, they were also requested to make their final estimation of the same test scores so that they could correct their previous predic-tion if they desired.

Moreover, students were also informed that only their second estimation would be used in the final valuation process to determine their bonus points. In this way, the pre- and post-examination assessments made it possible to research how students are able to reconsider their knowledge after the tests. Thus, in order to exemplify the robustness check of our estimations, we measured self-assessment by using various methodologies. In this paper, besides some descriptive statistics, (linear and binary logistic) regression models and independent samples, t-tests are frequently analysed to highlight the distinctions among our evaluations. 


\section{RESULTS}

Before testing our earlier hypotheses, in Table 1 we summarise and provide an overview of the descriptive statistics (minimum, maximum, mean and standard deviation values) of the pre- and post-examination self-estimations of students and the tutor-assigned test scores.

Tab. 1 - Descriptive statistics of pre- and post-estimated and real test scores, Source: based on our estimations

\begin{tabular}{|c|c|c|c|c|c|c|c|}
\hline Estimations & TYPE & ASSESSMENT & $\mathrm{N}$ & Min & Max & Mean & Std. Dev. \\
\hline \multirow{3}{*}{ Traditional } & \multirow{3}{*}{ TRAD } & TUTOR & 135 & 0 & 50 & 26.23 & 12.85 \\
\hline & & PRE & 135 & 0 & 49 & 29.35 & 10.73 \\
\hline & & POST & 135 & 0 & 50 & 25.33 & 12.51 \\
\hline \multirow{12}{*}{ Moodle } & \multirow{3}{*}{$\mathrm{T} / \mathrm{F}$} & TUTOR & 135 & 3 & 10 & 7.78 & 1.45 \\
\hline & & PRE & 135 & 4 & 10 & 7.33 & 1.39 \\
\hline & & POST & 135 & 3 & 10 & 7.32 & 1.63 \\
\hline & \multirow{3}{*}{$\mathrm{MC}$} & TUTOR & 135 & 2 & 10 & 6.70 & 1.98 \\
\hline & & PRE & 135 & 4 & 10 & 6.96 & 1.46 \\
\hline & & POST & 135 & 2 & 15 & 7.07 & 1.78 \\
\hline & \multirow{3}{*}{ PRAC } & TUTOR & 135 & 1 & 18 & 8.47 & 4.21 \\
\hline & & PRE & 135 & 1 & 19 & 11.92 & 3.15 \\
\hline & & POST & 135 & 0 & 20 & 11.31 & 3.83 \\
\hline & \multirow{3}{*}{ Total } & TUTOR & 135 & 10 & 37 & 22.96 & 6.10 \\
\hline & & PRE & 135 & 9 & 36 & 26.21 & 4.81 \\
\hline & & POST & 135 & 0 & 38 & 25.50 & 6.38 \\
\hline
\end{tabular}

Note: TRAD - traditional tests, T/F - True and False, MC - Multiple Choice questions, PRAC - Practical exercises

\subsection{Testing the $\mathrm{H} 1$ and $\mathrm{H} 2$ hypotheses}

According to the $\mathrm{H}_{1}$ and $\mathrm{H}_{2}$ sub-hypotheses, linear regression models should be tested in which the dependent variable is the accuracy of the students' pre- and post-estimations (ADIFTSCPRE and ADIFTSCPOST measured by the absolute difference value of the stu-dent-estimated and the tutor-assigned test scores). Annex 1 in the appendix contains the list of further dependent variables to explain each element of the contents tested in our models.

The FINALTRASC, FINALT\&FSC, FINALMCSC, FINALPRASC and FINALTOTSC are substituted by the tutor-assigned test scores of different exam types as independent variables. In our regression models the, dummies of SEX and MAJOR1 are selected to maximize the 'goodness of fit' ( $\mathrm{R}^{2}$, as the percentage of the response variable variation that is explained by a linear regression model). Consequently, the pre- and post-accuracy of self-assessment is estimated independently in two models. The first (Model 1) contains all the available inde-pendent variables and the other (Model 2) is restricted to those that are at least significant at the $10 \%$ p-level. 
Moreover, there are additional coefficients that are not included in our re-stricted models of self-assessment features of financial knowledge. Hence, the validity of our conclusions is limited by the bias caused by exclusion of certain of these variables.

Tab. 2 - Results of the linear regression models for the pre-examination of self-assessment, Source: based on our estimations

\begin{tabular}{|c|c|c|c|c|c|c|c|c|c|c|}
\hline $\begin{array}{l}\text { Independent } \\
\text { variable }\end{array}$ & \multicolumn{2}{|c|}{ ADIFTRAPRE } & \multicolumn{2}{|c|}{ ADIFT\&FPRE } & \multicolumn{2}{|c|}{ ADIFMCPRE } & \multicolumn{2}{|c|}{ ADIFPRAPRE } & \multicolumn{2}{|c|}{ ADIFTOTPRE } \\
\hline \multirow{2}{*}{$\begin{array}{l}\text { Dependent } \\
\text { variables }\end{array}$} & \multicolumn{2}{|c|}{ Model } & \multicolumn{2}{|c|}{ Model } & \multicolumn{2}{|c|}{ Model } & \multicolumn{2}{|c|}{ Model } & \multicolumn{2}{|c|}{ Model } \\
\hline & 1 & 2 & 1 & 2 & 1 & 2 & 1 & 2 & 1 & 2 \\
\hline \multirow{3}{*}{ CONSTANT } & 11.52 & 11.54 & 1.47 & 1.65 & 2.39 & 2.85 & 8.21 & 8.11 & 13.47 & 13.63 \\
\hline & 7.66 & 10.11 & 2.81 & 3.21 & 5.48 & 7.25 & 11.38 & 14.61 & 9.39 & 10.72 \\
\hline & $* * *$ & $* * *$ & $* * *$ & $* * *$ & $* * *$ & $* * *$ & $* * *$ & $* * *$ & $* * *$ & $* * *$ \\
\hline \multirow{3}{*}{ FINALSC } & -0.19 & -0.19 & -0.02 & -0.02 & -0.16 & -0.16 & -0.41 & -0.41 & -0.35 & -0.35 \\
\hline & -4.83 & -4.92 & \multirow{2}{*}{-0.39} & \multirow{2}{*}{-0.35} & -2.91 & -3.31 & -6.63 & -7.01 & -6.36 & -6.52 \\
\hline & $* * *$ & $* * *$ & & & $* * *$ & $* * *$ & $* * *$ & $* * *$ & $* * *$ & $* * *$ \\
\hline \multirow{2}{*}{ SEX } & -0.57 & & 0.42 & & -0.37 & & 0.18 & & 0.25 & \\
\hline & -0.53 & & $2.14 *$ & & -1.64 & & 0.35 & & 0.38 & \\
\hline \multirow{2}{*}{ MAJOR1 } & -0.56 & & -0.12 & & 0.75 & & -0.31 & & 0.12 & \\
\hline & 0.31 & & -0.53 & & $2.76^{*}$ & & -0.46 & & 0.14 & \\
\hline $\mathrm{R}^{2}$ & 0.16 & 0.16 & 0.03 & 0.01 & 0.12 & 0.06 & 0.27 & 0.27 & 0.24 & 0.24 \\
\hline Adjusted $\mathrm{R}^{2}$ & 0.14 & 0.15 & 0.01 & 0.01 & 0.11 & 0.06 & 0.25 & 0.26 & 0.22 & 0.24 \\
\hline Durbin Watson & 1.846 & 1.831 & 1.976 & 1.931 & 2.077 & 2.052 & 1.501 & 1.514 & 1.601 & 1.601 \\
\hline
\end{tabular}

Note: Heteroscedasticity robust t-statistics are also reported. Letters in the upper index refer to significance: ***: significance at 1 per cent, **: 5 per cent, *: 10 per cent. P-values without an index mean that the coefficient is not significant even at the 10 per cent level.

The statistics of the regression models are shown in Tables 2 and 3 for the pre- and post-test estimations. Almost everywhere in both models, we found significant linear connections be-tween the accuracy of students' prediction and the tutor's assessment. The only exception was with true and false questions where no relationship existed in our models. 
Tab. 3 - Results of the linear regression models for the post-examination of self-assessment, Source: based on our estimations

\begin{tabular}{|c|c|c|c|c|c|c|c|c|c|c|}
\hline $\begin{array}{l}\text { Independent } \\
\text { variable }\end{array}$ & \multicolumn{2}{|c|}{ ADIFTRAPOST } & \multicolumn{2}{|c|}{ ADIFT\&FPOST } & \multicolumn{2}{|c|}{ ADIFMCPOST } & \multicolumn{2}{|c|}{ ADIFPRAPOST } & \multicolumn{2}{|c|}{ ADIFTOTPOST } \\
\hline \multirow{2}{*}{$\begin{array}{l}\text { Dependent } \\
\text { variables }\end{array}$} & \multicolumn{2}{|c|}{ Model } & \multicolumn{2}{|c|}{ Model } & \multicolumn{2}{|c|}{ Model } & \multicolumn{2}{|c|}{ Model } & \multicolumn{2}{|c|}{ Model } \\
\hline & 1 & 2 & 1 & 2 & 1 & 2 & 1 & 2 & 1 & 2 \\
\hline \multirow{3}{*}{ CONSTANT } & 5.22 & 5.79 & 1.83 & 1.91 & 3.01 & 2.83 & 6.14 & 6.16 & 10.61 & 10.73 \\
\hline & 4.44 & 6.49 & 2.78 & 3.05 & 6.67 & 7.34 & 9.66 & 12.58 & 8.21 & 8.91 \\
\hline & $* * *$ & $* * *$ & $* * *$ & $* * *$ & $* * *$ & $* * *$ & $* * *$ & $* * *$ & $* * *$ & $* * *$ \\
\hline \multirow[b]{2}{*}{ FINALSC } & 0.01 & 0.02 & -0.06 & -0.05 & -0.17 & -0.19 & -0.25 & -0.25 & -0.25 & -0.25 \\
\hline & 0.58 & 0.74 & -0.76 & -0.72 & $\begin{array}{l}-3.13 \\
* * *\end{array}$ & $\begin{array}{l}-3.41 \\
* * *\end{array}$ & $\begin{array}{l}-4.65 \\
* * *\end{array}$ & $\begin{array}{l}-4.87 \\
* * *\end{array}$ & $\begin{array}{l}-4.81 \\
* * *\end{array}$ & $\begin{array}{l}-4.91 \\
* * *\end{array}$ \\
\hline \multirow{2}{*}{ SEX } & 0.46 & & 0.13 & & -0.37 & & 0.27 & & 0.39 & \\
\hline & 0.54 & & 0.54 & & -1.59 & & 0.59 & & 0.59 & \\
\hline \multirow{2}{*}{ MAJOR1 } & 0.47 & & 0.11 & & 0.03 & & -0.21 & & -0.04 & \\
\hline & 0.46 & & 0.39 & & 0.11 & & -0.35 & & -0.05 & \\
\hline $\mathrm{R}^{2}$ & 0.01 & 0.01 & 0.01 & 0.01 & 0.09 & 0.08 & 0.15 & 0.15 & 0.15 & 0.15 \\
\hline Adjusted $\mathrm{R}^{2}$ & 0.01 & 0.01 & 0.01 & 0.01 & 0.07 & 0.07 & 0.13 & 0.14 & 0.14 & 0.14 \\
\hline Durbin Watson & 1.804 & 1.829 & 1.888 & 1.893 & 2.088 & 2.064 & 1.901 & 1.924 & 1.807 & 1.816 \\
\hline
\end{tabular}

Note: Heteroscedasticity robust t-statistics are also reported. Letters in the upper index refer to significance: ***: significance at 1 per cent, **: 5 per cent, $*: 10$ per cent. P-values without an index mean that the coefficient is not significant even at the 10 per cent level

Essentially, the effect of tutor-assigned final scores on the absolute value of the differences between self and tutor assessment does not seem to be large (ranging from -0.19 to -0.41), however, in our models, the student results correlated negatively with accuracy.

Consequently, we can accept the $\mathrm{H}_{1}$ and $\mathrm{H}_{2}$ hypotheses; i.e., the higher-achieving students seem to be able to predict and evaluate their examination results more accurately than their lower-achieving fellows. Thus, in these models, neither gender (SEX) nor major (MAJOR1) have a significant effect on accuracy.

The additional $\left(\mathrm{H}_{3}\right)$ and $\left(\mathrm{H}_{4}\right)$ sub-hypotheses, which focused directly on self-estimation relating to the extent of estimation errors, are not independent of their positive sign. In this case, we are also assuming that higher-achieving students tend to overestimate their examina-tion results. Hence, the difference between the students' evaluated score and the score as-signed by the tutor is positive. However, in order to identify relationship between the stu-dents' achievement and the accuracy with which they overestimate their own performance, ceteris paribus, a binary logistic regression method might be an appropriate tool for our anal-ysis.

In all observed models (see Tables 4 and 5), the dependent variable indicates the likelihood of students' over-assessment. Those cases where the students evaluate their own performances accurately are estimated without an error and left out of the sample. The proportion of vari-ance 
explained by the predictors (measured by Cox and Shell's, and Nagelkerke's pseudo R ${ }^{2}$ and $\mathrm{R}^{2}$ change) of the binary logistic regression models are relatively high - indeed, high enough to agree with our results.

However, for every one-unit increase in the tutor-assigned test scores (so, for every additional point, and holding all other independent variables constant), we expect a decrease in the pre- and post-examined self-assessment differences of traditional and Moodle exams. Moreover, we also found out that on the Moodle test, higher-achieving students predict and evaluate their results more accurately than in the traditional tests.

All in all, higher-achieving students overestimate their own pre-and post-examination performance in our models, so we can accept the $\mathrm{H}_{3}$ and $\mathrm{H}_{4}$ hypotheses, as well. Meanwhile, there is no clear and significant relationship between genders at the stages of self-assessment. Indeed, more sophisticated methods are needed to analyze the ways in which students esti-mate their self-assessment of their accountancy knowledge when dividing the sample by two genders.

Therefore, independent sample t-tests are used on pre- and post-examination assessments to ascertain whether female or male students tend to estimate their own knowledge more highly than the total tutor-assigned scores. According to the standardized absolute value of the dif-ference between the students' pre-examination and the tutor-assigned estimation by gender, we found the following results (see Table 6). Although male students seem to overestimate their own scores at the pre-examination stage (we realized in our estimations that the average mean difference of men was always positive, while it was negative for women), according to the t-tests, there is no significant difference between the sexes in our examinations (the only exceptions being the practical and traditional exams at the pre- and post-examination stage).

Consequently, no significant gender differences in averages can be found between the tutors and student's pre- and post-examination scores. In other words, it cannot be disproved that the genders self-assessed indifferently and irrespectively of the type of questions. In this case, all of the sub-hypotheses $\left(\mathrm{H} 2_{1}, \mathrm{H} 2_{2}, \mathrm{H}_{2}\right.$ and $\left.\mathrm{H} 2_{4}\right)$ should be rejected.

Tab. 4 - Results of the binary logistic regression models for the pre-examination of self-assessment, Source: based on our estimations

\begin{tabular}{|c|c|c|c|c|c|c|c|c|c|c|}
\hline Independent & \multicolumn{2}{|c|}{ OETRAPRE } & \multicolumn{2}{|c|}{ OETT\&FPRE } & \multicolumn{2}{|c|}{ OETMCPRE } & \multicolumn{2}{|c|}{ OETPRAPRE } & \multicolumn{2}{|c|}{ OETTOTPRE } \\
\hline Dependent & Model & Model & Model & Model & Model & Model & Model & Model & Model & Model \\
\hline variables & 1 & 2 & 1 & 2 & 1 & 2 & 1 & 2 & 1 & 1 \\
\hline \multirow{3}{*}{ CONSTANT } & -1.99 & -2.00 & 7.21 & 6.99 & 6.69 & 7.08 & 5.69 & 5.35 & 7.72 & 7.29 \\
\hline & $(10.69)$ & (15.03) & (20.18) & $(21.44)$ & $(25.88)$ & (31.99) & $(25.55)$ & $(33.65)$ & $(32.29)$ & (33.38) \\
\hline & $* * *$ & $* * *$ & $* * *$ & $* * *$ & $* * *$ & $* * *$ & $* * *$ & $* * *$ & $* * *$ & $* * *$ \\
\hline \multirow{3}{*}{ FINALSC } & -0.06 & -0.06 & -1.07 & -1.06 & -1.18 & -1.11 & -0.43 & -0.42 & -0.27 & -0.27 \\
\hline & (12.81) & $(13.42)$ & (25.77) & $(26.53)$ & $(34.46)$ & $(35.45)$ & (25.14) & $(26.99)$ & $(27.76)$ & $(29.92)$ \\
\hline & $* * *$ & $* *$ & $* * *$ & $* * *$ & $* * *$ & $* * *$ & $* * *$ & $* * *$ & $* * *$ & $* * *$ \\
\hline \multirow{2}{*}{ SEX } & 0.26 & & 0.36 & & -0.12 & & -0.51 & & -0.72 & \\
\hline & 0.43 & & 0.47 & & 0.05 & & 0.87 & & 2.02 & \\
\hline
\end{tabular}




\begin{tabular}{|c|c|c|c|c|c|c|c|c|c|c|}
\hline & -0.26 & & -0.44 & & 1.11 & & 0.02 & & 0.05 & \\
\hline MAJOR1 & 0.28 & & 0.44 & & $\begin{array}{c}(3.102) \\
*\end{array}$ & & 0.00 & & 0.01 & \\
\hline Cox and Shell $\mathrm{R}^{2}$ & 0.12 & 0.12 & 0.28 & 0.27 & 0.43 & 0.42 & 0.30 & 0.29 & 0.31 & 0.30 \\
\hline Nagelkerke R2 & 0.16 & 0.16 & 0.39 & 0.39 & 0.58 & 0.56 & 0.44 & 0.44 & 0.44 & 0.42 \\
\hline $\mathrm{R}^{2}$ change & 0.09 & 0.09 & 0.27 & 0.26 & 0.41 & 0.39 & 0.32 & 0.31 & 0.30 & 0.28 \\
\hline Omnibus $\chi^{2}$ test & $\begin{array}{c}16.98 \\
* * *\end{array}$ & $\begin{array}{c}16.35 \\
* * *\end{array}$ & $\begin{array}{c}43.55 \\
* * *\end{array}$ & $\begin{array}{c}42.58 \\
* * *\end{array}$ & $\begin{array}{c}76.08 \\
* * *\end{array}$ & $\begin{array}{c}72.73 \\
* * *\end{array}$ & $\begin{array}{l}47.99 \\
* * *\end{array}$ & $\begin{array}{c}46.60 \\
* * *\end{array}$ & $\begin{array}{c}50.44 \\
* * *\end{array}$ & $\begin{array}{c}48.38 \\
* * *\end{array}$ \\
\hline HL $\chi^{2}$ test & 13.35 & 23,23 & 3.87 & 4.87 & 7.29 & 4.25 & 26.01 & 18.01 & 6.53 & 27.95 \\
\hline
\end{tabular}

Note: Heteroscedasticity robust Wald-statistics are in the parentheses. Letters in the upper index refer to significance: ***: significance at 1 percent, **: 5 percent, *: 10 percent. P-values without an index mean that the coefficient is insignificant even at the 10 percent level. HL: Hosmer and Lemeshow $\chi^{2}$ test.

Tab. 5 - Results of the binary logistic regression models for the post-examination of self-assessment, Source: based on our estimations

\begin{tabular}{|c|c|c|c|c|c|c|c|c|c|c|}
\hline $\begin{array}{l}\text { Independent } \\
\text { variable }\end{array}$ & \multicolumn{2}{|c|}{ OETRAPRE } & \multicolumn{2}{|c|}{ OETT\&FPRE } & \multicolumn{2}{|c|}{ OETMCPRE } & \multicolumn{2}{|c|}{ OETPRAPRE } & \multicolumn{2}{|c|}{ OETTOTPRE } \\
\hline Dependent & Model & Model & Model & Model & Model & Model & Model & Model & Model & Model \\
\hline variables & 1 & 2 & 1 & 2 & 1 & 2 & 1 & 2 & 1 & 2 \\
\hline \multirow{3}{*}{ CONSTANT } & 0.40 & 0.40 & 3.35 & 3.84 & 6.69 & 3.78 & 2.97 & 3.01 & 3.52 & 3.42 \\
\hline & 047 & 000 & (13.94) & $(9.09)$ & (25.88) & (20.93) & (17.94) & (28.78) & $(16.17)$ & (17.21) \\
\hline & 0.47 & 0.70 & $* * *$ & $* * *$ & $* * *$ & $* * *$ & $* * *$ & $* * *$ & $* * *$ & $* * *$ \\
\hline \multirow{3}{*}{ FINALSC } & -0.04 & -0.03 & -0.62 & -0.59 & -0.62 & -0.61 & -0.23 & -0.22 & -0.12 & -0.12 \\
\hline & $(5.92)$ & $(5.10)$ & $(24.75)$ & (14.85) & $(24.75)$ & (25.18) & $(15.46)$ & $(26.99)$ & (12.34) & (13.45) \\
\hline & $* *$ & $* *$ & $* * *$ & $* * *$ & $* * *$ & $* * *$ & $* * *$ & $* * *$ & $* * *$ & $* * *$ \\
\hline \multirow[b]{2}{*}{ SEX } & -1.07 & & -0.13 & & -0.13 & & -0.25 & & -0.33 & \\
\hline & $\begin{array}{c}(6.97) \\
* *\end{array}$ & & 0.09 & & 0.09 & & 0.58 & & 0.64 & \\
\hline \multirow{2}{*}{ MAJOR1 } & 0.99 & & 0.74 & & 0.74 & & 0.44 & & 0.13 & \\
\hline & $(3.61)^{*}$ & & 2.03 & & 2.02 & & 0.44 & & 0.06 & \\
\hline Cox and Shell $\mathrm{R}^{2}$ & 0.11 & 0.04 & 0.12 & 0.12 & 0.23 & 0.22 & 0.14 & 0.29 & 0.11 & 0.11 \\
\hline Nagelkerke $\mathrm{R}^{2}$ & 0.14 & 0.05 & 0.18 & 0.18 & 0.31 & 0.31 & 0.20 & 0.44 & 0.15 & 0.15 \\
\hline $\mathrm{R}^{2}$ change & 0.09 & 0.03 & 0.11 & 0.11 & 0.19 & 0.18 & 0.13 & 0.12 & 0.09 & 0.09 \\
\hline \multirow{2}{*}{ Omnibus $\chi^{2}$ test } & 14.78 & 5.30 & 17.92 & 34.33 & 35.44 & 34.33 & 20.41 & 19.33 & 16.11 & 15.44 \\
\hline & $* * *$ & $* * *$ & $* * *$ & $* * *$ & $* * *$ & $* * *$ & $* * *$ & $* * *$ & $* * *$ & $* * *$ \\
\hline HL $\chi^{2}$ test & 8.66 & 11.97 & 5.37 & 2.85 & 4.47 & 3.01 & 7.96 & 7.31 & 4.86 & 7.03 \\
\hline
\end{tabular}

Note: Heteroscedasticity robust Wald-statistics are in the parentheses. Letters in the upper index refer to significance: ***: significance at 1 percent, **: 5 percent, *: 10 percent. P-values without an index mean that the coefficient is not significant even at the 10 percent level. HL: Hosmer and Lemeshow $\chi^{2}$ test. 
Tab 6 - Comparison of female and male self-estimation with independent t-test, Source: own

\begin{tabular}{|c|c|c|c|c|c|c|c|}
\hline \multirow[t]{2}{*}{ Type } & \multirow{2}{*}{$\begin{array}{l}\text { Dependent } \\
\text { vari-ables }\end{array}$} & \multirow{2}{*}{$\begin{array}{c}\text { Levene's } \\
\text { F }\end{array}$} & \multirow[t]{2}{*}{$\mathrm{t}$} & \multirow{2}{*}{$\begin{array}{l}\text { Mean } \\
\text { Diff. }\end{array}$} & \multirow[t]{2}{*}{ S. E. M. } & \multicolumn{2}{|c|}{$\begin{array}{l}95 \% \text { Conf. int. } \\
\text { of the Diff. }\end{array}$} \\
\hline & & & & & & Lower & Upper \\
\hline \multirow{5}{*}{ Pre } & Traditional & 0.06 & 0.56 & 0.10 & 0.18 & -0.26 & 0.46 \\
\hline & True and False & 3.32 & 0.54 & 0.09 & 0.17 & -0.24 & 0.42 \\
\hline & Multiple choice & 2.72 & 1.12 & 0.20 & 0.18 & -0.16 & 0.56 \\
\hline & Practical & 0.89 & $2.05^{* *}$ & 0.37 & 0.18 & 0.01 & 0.72 \\
\hline & Total & 1.30 & $1.99 * *$ & 0.36 & 0.18 & 0.00 & 0.71 \\
\hline \multirow{5}{*}{ Post } & Traditional & 1.09 & $2.09 * *$ & 0.37 & 0.18 & 0.02 & 0.73 \\
\hline & True and False & 0.14 & -0.75 & -0.14 & 0.18 & -0.49 & 0.22 \\
\hline & Multiple choice & 4.38 & 1.08 & 0.21 & 0.20 & -0.18 & 0.60 \\
\hline & Practical & 0.48 & 1.21 & 0.22 & 0.18 & -0.14 & 0.57 \\
\hline & Total & 0.50 & 1.00 & 0.18 & 0.18 & -0.18 & 0.54 \\
\hline
\end{tabular}

Note: $\mathrm{N}=135$ (47 males, 88 females) ${ }^{*} \mathrm{p}<0.1$; ** $\mathrm{p}<0.05$; *** $\mathrm{p}<0.001$

\section{CONCLUSIONS}

Making appropriate management decisions is especially critical for today's competitive busi-ness environment. These challenges primarily focus on ensuring better education and training of accountants to support companies. The practice of accounting is changing rapidly, and this study highlights the fact that contemporary competences are insufficient for educating profes-sional accountants in the twenty-first century.

Technological adaptation and innovation, the main drivers of economic growth in developed countries are proving to be important competitiveness factors (Chen \& Dahlman, 2004). Not surprisingly, policymakers are interested in searching for effective solutions to improve the competitiveness levels of HEIs through providing up-to-date learning opportunities for their future voters. The ways in which higher education applies new technologies for learning pur-poses is related to how assessment is perceived. Therefore, providing any information about the accuracy of self-assessment in HEIs should support their competitiveness.

This paper has elaborated on the importance of self-assessment in ensuring the effective implementation of new technologies in accountancy exams, so as to enhance indirectly the competitiveness of higher education. In this study, the first objective was to analyze how those students who have studied accountancy can estimate their examination results in terms of their knowledge. In our models, the higher-achieving students seemed to predict and evaluate their examination results more accurately and tended to overestimate their examination results less than their lower-achieving peers. This is in accordance with the conclusions of Kruger and Dunning (1999) and Karnilowicz (2012).

We also highlighted that higher-achieving students predict and evaluate their results more accurately on Moodle tests than traditional test versions. Although professionals often refer to the 
need for learner-centered environments, in particular the applications of digital technolo-gies, it is still rarely noted as a functioning methodology in higher education. Essentially, we can claim that innovative techniques support more flexible, time-effective teaching, learning and examination processes than the backgrounds provided previously, such as formative as-sessment and feedback for accountants.

Consequently, this paper contributes to a better understanding of enhancing new digital technologies, which include a wide range of self-assessment methods in higher education. This is one of the most desirable policy responses to empower better auditing performances, to in-crease accountants' employability and to enhance the competiveness of HEIs and enterprises.

Finally, from another perspective, we focused on disparities in self-assessment by gender, which can vary across specific socio-economic groups. The results of this analysis did not provide clear evidence that disparities exist in self-estimation in this sense. In some cases, women were less likely to overestimate their results, which means they have a more realistic attitude before and after their accounting exams. Although Sistrom et al. (2003) and Macdon-ald (2004) also identified a higher tendency towards self-overestimation in the case of male students, in our models it cannot be clearly proved that the two genders assessed differently.

One of the main limitations of our study is that other important factors, which can influence directly our model specifications, are not included due to a restricted access to data. Moreo-ver, we cannot draw universal conclusions to identify the best teaching practices with respect to the accuracy of self-assessment in higher education. From another point of view, the exist-ing differences between nationalities, cultures or in other academic areas in self-evaluation represent good opportunities for further research.

\section{References}

1. Abbasi, N. (2013). Competency Approach to Accounting Education: A global view. Journal of Finance and Accountancy, 13 (1), 1-18.

2. American Accounting Association (AAA) (1986). Committee on Future Structure, Content, and Scope of Accounting Education. Future Accounting Education: Preparing for the Expanding Profession. Issues in Accounting Education (Spring), 168-195.

3. Black, W. H. (2012). The Activities of the Pathways Commission and the Historical Context for Changes in Accounting Education. Issues in Accounting Education, 27 (3), 601-625. http://dx.doi.org/10.2308/ISSUES-11-123.1.

4. Chen, D., Dahlman, C. (2004). Knowledge and Development: A Cross-section Review. Policy Research Working Paper \#3366. Washington, DC: World Bank.

5. European Commission (EC) (2009). Notices from European Union Institutions and Bodies, Council Conclusions of 12 May 2009 on a Strategic Framework for European Cooperation in Education and training (ET 2020). 119 (2), 1-9.

6. Everett, M. S. (1983). Influence of Trait Anxiety on Self-grading. Educational Directions, 8 (1), $4-9$. 
7. Gibbs, G. (1999). Using Assessment Strategically to Change the Way Students Learn. In: Brown, S. \& Glasner, A. (eds.) Assessment Matters in Higher Education: Choosing and Using Diverse Approaches. Buckingham: SRHE and the Open University Press, 41-52.

8. Hobohm, C., Cochrane, S., Basson, M., \& Basnet, B. (2012). Students' Self-assessment of Assignments - Is It worth It? Proceedings of the 2012 A AEE Conference. Melbourne, Victoria.

9. Karnilowicz, W. (2012). A Comparison of Self-assessment and Tutor Assessment of Undergraduate Psychology Students. Social Behaviour and Personality: An International Journal, 40 (4), 591-604.

10. Kirkwood, A., \& Price, L. (2011). The Influence Upon design of Differing Conceptions of Teaching and Learning with Technology. In: Olofsson, A. D., C Lindberg, J. O. (eds.) In-formed Design of Educational Technologies in Higher Education: Enhanced Learning and Teaching. Hershey, PA: IGI Global.

11. Kiss Zs. (2014) Job Search Time: the Indicator of Employability. Journal of Research in Business and Management (Quest Journals), 2 (4), 1-9.

12. Kun, A. I. (2016). A Comparison of Self versus Tutor Assessment among Hungarian un-dergraduate business students. Assessment \& Evaluation in Higher Education, 41 (3), 1-18. http://dx.doi.org/10.1080/02602938.2015.1011602.

13. Kruger, J., \& Dunning, D. (1999). Unskilled and Unaware of It: How Difficulties in Recognizing One's Own Incompetence Lead to Inflated Self-assessments. Journal of Personality and Social Psychology, 77 (6), 1121-1134.

14. Macdonald, A. (2004). Student Self-evaluation of Coursework Assignments: A Route to Better Perception of Quality. Learning and Teaching in Higher Education, 1 (1), 102-107.

15. McPeak, D., Pincus, K. V., \& Sundem, G. L. (2012). The International Accounting Education Standards Board: Influencing Global Accounting Education. Issues in Accounting Education, 27 (3), 743-750. http://dx.doi.org/10.2308/iace-50121.

16. O’Neill, P., Holzer, C., \& Lynn, D. J. (2006). Relationships between Self-assessment Skills, Test Performance, and Demographic Variables in Psychiatry Residents. Advances in Health Sciences Education, 11 (1), 51-60. http://dx.doi.org/10.1007/s10459-005-5473-4.

17. Ross, J. A. (2006). The Reliability, Validity, and Utility of Self-assessment. Practical Assessment. Research \& Evaluation, 11 (10), 1-13.

18. Sistrom, C. L., Magyari, E. J., Kellner, R. K., \& Edwards, R. K. (2003). Medical Student Self-assessment of Performance on an Obstetrics and Gynaecology Clerkship. American Journal of Obstetrics and Gynaecology, 188 (4), 1078-1082.

19. Strawser, J. R., Stith, M. T., Rayburn, J. D., Murphy, L. A., Ezzell, W. F., \& Behn, B. (2012). The Pathways Commission on Accounting Higher Education: Charting a National Strategy for the Next Generation of Accountants. Issues in Accounting Education, 27 (3), pp. 595-600. http://dx.doi.org/10.2308/1558-7983-27.3.593.

20. Zimmerman, B. J., \& D. H. Schunk. (2001). Self-regulated Learning and Academic Achievement: Theoretical Perspectives. Mahwah, NJ: Lawrence Erlbaum.

21. Walker, R., Voce, J., Nicholls, J., Swift, E., Jebar, A., Horrigan, S., \& Vincent P. (2014). Survey of Technology Enhanced Learning for Higher Education in the UK. UCISA Survey 


\section{Contact information}

Dr. Domicián Máté, PbD

Economics and Business Faculty, Accounting and Finance Institute,

University of Debrecen,

Böszörményi Str. 138. Debrecen, Hungary

E-mail:mate.domician@econ.unideb.bu

Dr. Éva Darabos, PhD

Economics and Business Faculty, Accounting and Finance Institute, University of Debrecen,

Böszörményi Str. 138. Debrecen, Hungary

E-mail:eva.darabos@econ.unideb.hu 


\section{Appendix}

Annex 1. Explanation of variables

\begin{tabular}{|c|c|}
\hline Variables & Explanation \\
\hline SEX & 1 if the student is female, 0 if male \\
\hline MAJOR1 & 1 if the student is on the Agrarian Informatics Engineer major, 0 if not \\
\hline ADIFTRAPRE & $\begin{array}{l}\text { Absolute value of the difference between the student's pre-examination and } \\
\text { the tutor assigned estimation of the traditional test scores }\end{array}$ \\
\hline ADIFTRAPRE & $\begin{array}{l}\text { Absolute value of the difference between the student's post-examination and } \\
\text { the tutor assigned estimation of the traditional test scores }\end{array}$ \\
\hline ADIFT\&FPRE & $\begin{array}{l}\text { Absolute value of the difference between the student's pre-examination and } \\
\text { the tutor assigned estimation of the true or false test scores }\end{array}$ \\
\hline ADIFT\&FPOST & $\begin{array}{l}\text { Absolute value of the difference between the student's post-examination and } \\
\text { the tutor assigned estimation of the true or false test scores }\end{array}$ \\
\hline ADIFMCPRE & $\begin{array}{l}\text { Absolute value of the difference between the student's pre-examination and } \\
\text { the tutor assigned estimation of the multiple choice test scores }\end{array}$ \\
\hline ADIFMCPOST & $\begin{array}{l}\text { Absolute value of the difference between the student's post-examination and } \\
\text { the tutor assigned estimation of the multiple choice test scores }\end{array}$ \\
\hline ADIFPRAPRE & $\begin{array}{l}\text { Absolute value of the difference between the student's pre-examination and } \\
\text { the tutor assigned estimation of the practical test scores }\end{array}$ \\
\hline ADIFPRAPOST & $\begin{array}{l}\text { Absolute value of the difference between the student's post-examination and } \\
\text { the tutor assigned estimation of the practical test scores }\end{array}$ \\
\hline ADIFTOTPRE & $\begin{array}{l}\text { Absolute value of the difference between the student's pre-examination and } \\
\text { the tutor assigned estimation of the total test scores }\end{array}$ \\
\hline ADIFTOTPOST & $\begin{array}{l}\text { Absolute value of the difference between the student's post-examination and } \\
\text { the tutor assigned estimation of the total test scores }\end{array}$ \\
\hline FINAL(TRA)SC & Tutor-assigned final scores of the traditional questions \\
\hline FINAL(T\&F)SC & Tutor-assigned final scores of the true or false questions \\
\hline FINAL(MC)SC & Tutor-assigned final scores of the multiple choice questions \\
\hline FINAL(PRA)SC & Tutor-assigned final scores of the practical questions \\
\hline FINAL(TOT)SC & Tutor-assigned final scores of the total Moodle questions \\
\hline OETTRAPRE & $\begin{array}{l}1 \text { if the student overestimated his/her traditional test scores before the } \\
\text { exam, } 0 \text { if not }\end{array}$ \\
\hline OETTRAPOST & $\begin{array}{l}1 \text { if the student overestimated his/her traditional test scores after the exam, } \\
0 \text { if not }\end{array}$ \\
\hline OETT\&FPRE & $\begin{array}{l}1 \text { if the student overestimated his/her true or false test scores before the } \\
\text { exam, } 0 \text { if not }\end{array}$ \\
\hline OETT\&FPOST & $\begin{array}{l}1 \text { if the student overestimated his/her true or false test scores after the exam, } \\
0 \text { if not }\end{array}$ \\
\hline OETMCPRE & $\begin{array}{l}1 \text { if the student overestimated his/her multiple choice test scores before the } \\
\text { exam, } 0 \text { if not }\end{array}$ \\
\hline
\end{tabular}




\begin{tabular}{|c|c|}
\hline OETMCPOST & $\begin{array}{l}1 \text { if the student overestimated his/her multiple choice test scores after the } \\
\text { exam, } 0 \text { if not }\end{array}$ \\
\hline OETPRAPRE & $\begin{array}{l}1 \text { if the student overestimated his/her practical test scores before the exam, } \\
0 \text { if not }\end{array}$ \\
\hline OETPRAPOST & $\begin{array}{l}1 \text { if the student overestimated his/her practical test scores after the exam, } 0 \\
\text { if not }\end{array}$ \\
\hline OETTOTPRE & $\begin{array}{l}1 \text { if the student overestimated his/her total test scores before the exam, } 0 \text { if } \\
\text { not }\end{array}$ \\
\hline OETTOTPOST & $\begin{array}{l}1 \text { if the student overestimated his/her total test scores after the exam, } 0 \text { if } \\
\text { not }\end{array}$ \\
\hline DIFTRAPRE & $\begin{array}{l}\text { The difference between the student's pre-examination and the tutor as- } \\
\text { signed estimation of traditional exams }\end{array}$ \\
\hline DIFTRAPOST & $\begin{array}{l}\text { The difference between the student's post-examination and the tutor as- } \\
\text { signed estimation of traditional exams }\end{array}$ \\
\hline DIFT\&FPRE & $\begin{array}{l}\text { The difference between the student's pre-examination and the tutor as- } \\
\text { signed estimation of true or false questions }\end{array}$ \\
\hline DIFT\&FPOST & $\begin{array}{l}\text { The difference between the student's post-examination and the tutor as- } \\
\text { signed estimation of true or false questions }\end{array}$ \\
\hline DIFMCPRE & $\begin{array}{l}\text { The difference between the student's pre-examination and the tutor as- } \\
\text { signed estimation of multiple choice questions }\end{array}$ \\
\hline DIFMCPOST & $\begin{array}{l}\text { The difference between the student's post-examination and the tutor as- } \\
\text { signed estimation of multiple choice questions }\end{array}$ \\
\hline DIFPRAFPRE & $\begin{array}{l}\text { The difference between the student's pre-examination and the tutor as- } \\
\text { signed estimation of practical exercises }\end{array}$ \\
\hline DIFPRAPOST & $\begin{array}{l}\text { The difference between the student's post-examination and the tutor as- } \\
\text { signed estimation of practical exercises }\end{array}$ \\
\hline DIFTOTPRE & $\begin{array}{l}\text { The difference between the student's pre-examination and the tutor as- } \\
\text { signed total estimation }\end{array}$ \\
\hline DIFTOTPOST & $\begin{array}{l}\text { The difference between the student's post-examination and the tutor as- } \\
\text { signed total estimation }\end{array}$ \\
\hline
\end{tabular}

